\title{
KEGIATAN PEMBELAJARAN MENGGAMBAR BANGUNAN BAGI SISWA SMK DI KOTA MEDAN
}

\author{
Imam Faisal Pane ${ }^{1 *}$, Wahyu Abdillah ${ }^{1}$, Chichi Asda Artha ${ }^{1}$, Hesti Fibriasari ${ }^{2}$ \\ ${ }^{1}$ Departemen Arsitektur, Fakultas Teknik, Universitas Sumatera Utara, Padang Bulan, Medan 20155 Indonesia \\ ${ }^{2}$ Jurusan Bahasa Prancis, Fakultas Bahasa dan Seni, Universitas Negeri Medan \\ Jl. Willem Iskandar Pasar V-Kotak Pos No. 1589 - Medan 20221 \\ *Penulis Korespodensi : imam.faisal@usu.ac.id
}

\begin{abstract}
Abstrak
Artikel ini menjelaskan tentang kegiatan dari pengabdian masyarakat sebagai salah satu kegiatan TRI DHARMA perguruan tinggi. Kegiatan pengabdian ini dilakukan oleh dosen terhadap masyarakat yang membutuhkan terutama masyarakat diluar kampus. Pada kesempatan ini dilakukan kegiatan untuk para siswa Sekolah Menegah Kejuruan yang ada di Medan yaitu SMK Negeri 2 Medan dan SMK DWIWARNA Medan, kedua mitra ini memiliki jurusan menggambar bangunan/teknik. Masalah yang ada saat ini pada mitra adalah penerapan prinsip disain didalam kegitan menggambar bangunan belum optimal. Untuk itu solusi yang ditawarkan adalah mengadakan pelatihan untuk membekali para siswa ketrampilan menggambar lewat pendekatan disain. Metode pelaksanaan kegiatan ini adalah mengadakan sesi pelatihan dengan modul pelatihan CAD dan 3D Modelling dengan jadwal yang disesuaikan dengan kondisi sekolah. Kegiatan ini merupakan transfer ilmu pengetahuan di bidang CAD dan 3D Modelling yang juga dipelajari dan digunakan dalam proses pembelajaran di Departemen Arsitektur USU. Oleh karena itu pengetahuan ini diberikan dalam bentuk pelatihan agar dapat menambah wawasan dalam penguasaan teknologi terkini.
\end{abstract}

Kata kunci: SMK, Pelatihan, Menggambar Bangunan

\begin{abstract}
This article described the activities of community service as one of the activities of Three university's obligations. This devotional activity was done by lecturers to the community in need, especially the community outside of the campus. On this occasion, there were activities for Vocational High School students in Medan, SMK Negeri 2 Medan and SMK DWIWARNA Medan, both partners have building I engineering drawing major. The current problem with partners was the application of design principles in drawing the building which had not been optimal yet. For that case, the solution offered was conducting the training to equip the students with drawing skills through design approach. The method of implementation of this activity was holding a training session with CAD and $3 D$ Modeling training modules with a schedule associated to the school conditions. This activity was a transfer of science in the field of CAD and $3 D$ Modeling which was also studied and used in the learning process at the Department of Architecture USU. Therefore this knowledge was given in the form of training in order to add insight in the mastery of the latest technology.
\end{abstract}

Keywords: Vocational High School (SMK), Training, Building Drawing

\section{PENDAhuluan}

Keterampilan terhadap penguasaan teknologi informasi saat sekarang ini tidak dapat ditawar-tawar lagi. Perkembangan yang sangat cepat membutuhkan penyesuain yang cepat pula terhadap teknologi digital tersebut. Pada saat ini penggunaan teknologi informasi harus dikuasai mulai dari tingkat Sekolah Dasar sampai Perguruan Tinggi sebab teknologi akan membantu para siswa dan mahasiswa dalam proses belajar. Kurikulum pembelajaran sekarang ini dari mulai tingkat sekolah dasar sampai sekolah menengah dan universitas memiliki konten yang bersentuhan dengan teknologi informasi. Dari mulai penguasaan tentang hal yang dasar seperti penguasaan tentang hardware komputer sampai dengan software komputer dan masuk sebagai bagian dari kurikulum permbelajaran.

Penguasaan perangkat lunak (software) komputer akan membantu siswa karena dapat berfungsi sebagai alat untuk menunjang proses pembelajaran seperti penguasaan Microsoft Word akan membantu dalam pembuatan laporan dan proses edit yang cepat. Beberapa jurusan atau program studi baik di Sekolah Menengah Kejuruan (SMK) ataupun perguruan tinggi pasti sudah menggunakan teknologi informasi yang 
sesuai dengan jurusan atau program studi masingmasing.

Merujuk kepada penjelasan diatas pada Sekolah Menengah Kejuruan (SMK) yang memiliki jurusan menggambar dalam bangunan/teknik juga menggunakan alat bantu komputer dalam proses pembelajarannya. Untuk itu dalam pengabdian masyarakat ini akan dilakukan transfer ilmu pengetahuan di bidang ketrampilan menggambar bangunan dengan menggunakan perangkat lunak komputer. Penguasaan Computer Aided Design (CAD) akan coba digabungkan dengan penguasaan pembuatan 3D Modelling dengan menggunakan perangkat lunak yang sesuai, sehingga hasil daripada penggambaran dapat dilihat sebagai model 3D yang akan dapat dengan mudah dipahami oleh orang yang melihat gambar tersebut. Penggunaan CAD ini sangat membantu dalam proses disain objek tertentu dan perancangan bangunan (Manullang, 2015).

Penguasaan menggambar bangunan tidak hanya sekedar menarik garis tetapi yang paling penting adalah mengetahui dasar dari pada mendisain bangunan (Wahana Komputer, 2014). Apabila para siswa mengetahui dasar mendisain bangunan, akan menjadi nilai tambah dalam meningkatkan ketrampilan dalam menggambar bangunan. Foto dibawah ini memperlihatkan bahwa kedua sekolah telah memiliki fasilitas yang mendukung untuk melaksanakan pelatihan ini.
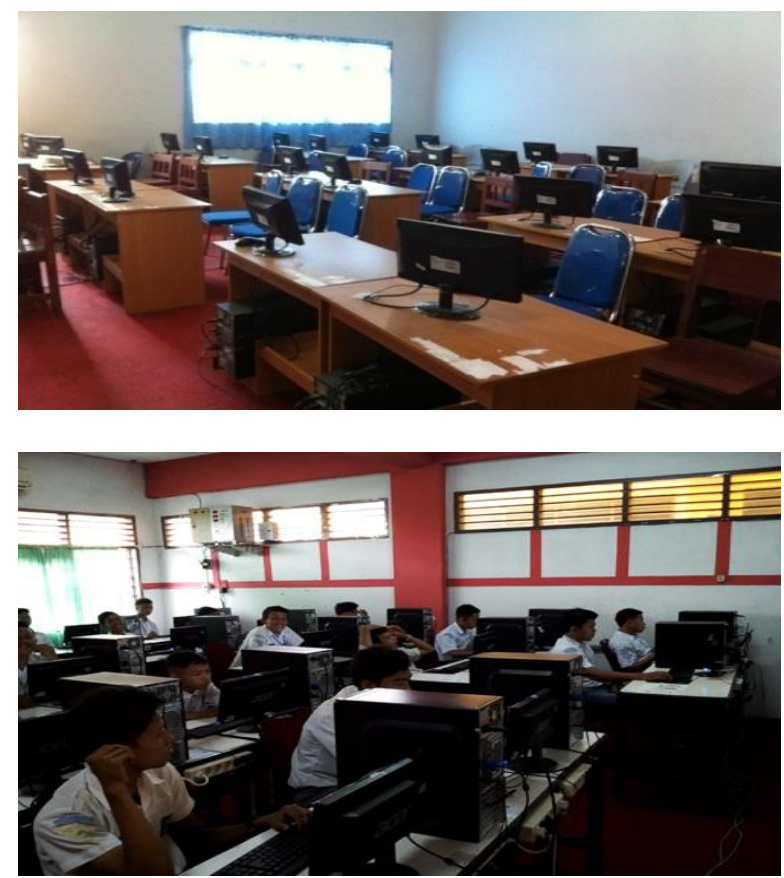

Gambar 2. Laboratorium Komputer SMK Dwiwarna Medan

Untuk itu, pengabdian masyarakat ini dilaksanakan pada tahun 2017 dengan 2 (dua) mitra yaitu SMK Negeri 2 Medan dan SMK Dwiwarna Medan yang memiliki jurusan yang sesuai dan tepat untuk dilakukan kegiatan ini yaitu jurusan menggambar banguanan/teknik (Gambar 1 dan 2).

\section{BAHAN DAN METODE}

Metode pelaksanaan dari pengabdian ini adalah kegiatan dilaksanakan di tempat mitra yaitu SMK Negeri 2 Medan dan SMK DWIWARNA MEDAN. Setelah mendapat persetujuan dari pihak sekolah dan penandatanganan surat pernyataan kesediaan bekerjasama, maka pelaksanaan pengabdian dapat dilakukan pada tahun 2017 setelah penandatanganan kontrak pengabdian antara Ketua Pelaksana Pengabdian dengan Ketua Lembaga Pengabdian Masyarakat USU selesai dilakukan. Pelaksanaan dilakukan dengan cara tutorial didalam kelas atau laboratorium dengan fasilitas komputer yang memadai dengan dilengkapi dengan LCD Projector dan layar untuk keperluan presentasi. Ruang kelas juga harus dilengkapi dengan white board atau papan tulis untuk keperluan pelatihan, semua fasilitas ini merupakan partisipasi dari mitra.

Pelatihan dilaksanakan pada satu sekolah dengan membagi kelas menjadi 2 (dua) grup yaitu Kelas $A$ dan Kelas B, masing-masing kelas akan mendapat materi CAD dan 3D Modelling. Kedua Sekolah mendapat materi dan jam waktu pelatihan yang sama sehingga penguasaan terhadap materi pelatihan diharapkan dapat tercapai pada akhir pelatihan. Pelaksanaan pelatihan menggunakan perangkat/modul pembelajaran yang berisikan materi penggunaan CAD dan 3D Modelling, materi ini diharapkan akan menambah wawasan siswa yang ikut pelatihan setalah terlebih dahulu tim pelaksana pengabdian berkonsultasi dengan pihak sekolah mengenai penguasaan materi siswa terhadap perangkat lunak tersebut. Modul yang dijadikan bahan pelatihan akan mudah diserap oleh siswa karena sudah bersinergi dengan materi yang mereka pelajari selama ini di sekolah.

Pelatihan ini tentu saja berkaitan dengan penguasaan software menggambar bangunan yang sering digunakan oleh dunia kerja di Indonesia. Seperti yang dijelaskan diatas penguasaan materi CAD dan 3D Modelling akan diberikan melalui kegiatan pengabdian masyarakat ini dengan tahapan pembelajaran yang disesuaikan dengan jadwal belajar para siswa di sekolah. Pelatihan menggambar bangunan ini dibagi menjadi 2 kegiatan besar yaitu CAD dan 3D Modelling. Kegiatan pelatihan ini mengikuti jadwal praktikum yang ada di sekolah, untuk itu terdapat perbedaan jadwal diantara 2 mitra sekolah. Pada SMK Negeri 2 jadwal pelatihan dilaksanakan pada Hari Selasa jam 09.00-10.30 dan Hari Jumat jam 10.20-11.40. Sedangkan kegiatan pada SMK Dwiwarna dilaksanakan pada hari yang sama yaitu Hari Jumat jam 08.40-10.00 dan 10.10-11.30 dengan materi CAD dan 3D Modelling. Pelaksanaan kegiatan dibagi menjadi 2 sesi dengan materi yang berbeda disetiap pertemuan, terdapat 8 (delapan) 
pertemuan pada tiap sesi CAD dan 3D Modelling (Tabel 1.)

Tabel 1. Materi Pelatihan 3D Modelling dan CAD

\begin{tabular}{|c|l|l|}
\hline NO & \multicolumn{1}{|c|}{ 3D Modelling } & \multicolumn{1}{c|}{ CAD } \\
\hline 1. & $\begin{array}{l}\text { Pengenalan interface dan } \\
\text { navigasi Sketchup }\end{array}$ & $\begin{array}{l}\text { Pengenalan } \\
\text { program CAD }\end{array}$ \\
\hline 2. & $\begin{array}{l}\text { Menggambar presisi di } \\
\text { bidang 2D }\end{array}$ & $\begin{array}{l}\text { Perintah - perintah } \\
\text { dasar CAD }\end{array}$ \\
\hline 3. & $\begin{array}{l}\text { Membuat permodelan } \\
\text { 3D dari gambar 2D }\end{array}$ & $\begin{array}{l}\text { Perintah - perintah } \\
\text { dasar CAD }\end{array}$ \\
\hline 4. & $\begin{array}{l}\text { Membuat permodelan } \\
\text { Memberi material pada } \\
\text { objek 3D }\end{array}$ & $\begin{array}{l}\text { Akurasi gambar, } \\
\text { block dan layer }\end{array}$ \\
\hline 5. & $\begin{array}{l}\text { Membuat permodelan } \\
\text { 3D rumit }\end{array}$ & Informasi gambar \\
\hline 6. & $\begin{array}{l}\text { Melakukan penyesuaian } \\
\text { scene dan style }\end{array}$ & $\begin{array}{l}\text { Konsep 3D dan } \\
\text { perintah dasar }\end{array}$ \\
\hline 8. & $\begin{array}{l}\text { Mengenal tampilan dan } \\
\text { navigasi layout } \\
\text { mempersiapkan } \\
\text { dokumen gambar kerja } \\
\text { Tans dan trik sketchup } \\
\text { dan layout }\end{array}$ & $\begin{array}{l}\text { Operasi Logika 3D } \\
\text { dan Surface }\end{array}$ \\
\hline
\end{tabular}

\section{HASIL DAN PEMBAHASAN}

Hasil yang dicapai adalah kesepakatan untuk melakukan kegiatan pelatihan kepada mitra pengabdian. Kesepakatan ini dituangkan dalam jadwal pelatihan yang disusun berdasarkan kebutuhan siswa. Pelaksanaan kegiatan ini berdasarkan pelajaran yang mereka terima disekolah sehingga dengan adanya kegiatan pelatihan ini akan membantu pemahaman mereka terhadap pelajaran yang mereka pelajari terutama ketrampilan dalam menggambar bangunan. Sedangkan luaran yang akan dicapai adalah srtikel yang ditulis berdasarkan hasil kegiatan ini dan dimasukkan kedalam jurnal yang memiliki ISSN.

Perguruan tinggi mempunyai TRI DHARMA perguruan tinggi yaitu pengajaran, penelitian dan pengabdian masyarakat. Ketiga pilar ini harus dilakukan oleh staf pengajar agar proses pembelajaran di perguruan tinggi dapat berjalan dengan baik dan semestinya. Peranan ketiga pilar ini tidak bisa dilepaskan satu persatu tetapi harus dilakukan dengan paralel agar ketiganya dapat bersinergi satu sama lain.

Proses transfer ilmu pengetahuan yang dilakukan dosen terhadap mahasiswa di kampus merupakan proses pengajaran yang dilaksanakan secara reguler di tiap semester. Untuk meningkatkan pengetahuan akan hal yang baru maka dosen didorong untuk melakukan penelitian agar penguasaan ilmu pengetahuan akan mengalami peningkatan bagi dosen secara langsung. Dari proses pengajaran dan penelitian ini maka ilmu pengetahuan yang telah dimiliki harus juga dapat dirasakan oleh masyarakat yang berada diluar perguruan tinggi, maka dari itu diperlukan kegiatan pengabdian masyarakat untuk mentransfer pengetahuan secara langsung kepada masyarakat yang membutuhkan (Gambar 3 dan 4).

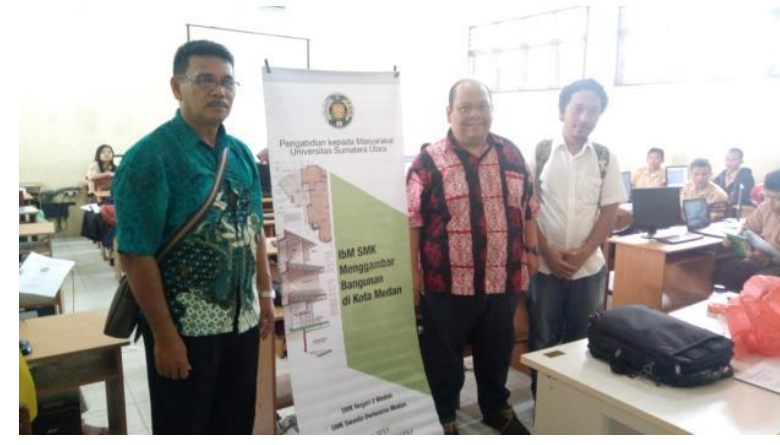

Gambar 3. Suasana Pelatihan di SMK Negeri 2 Medan

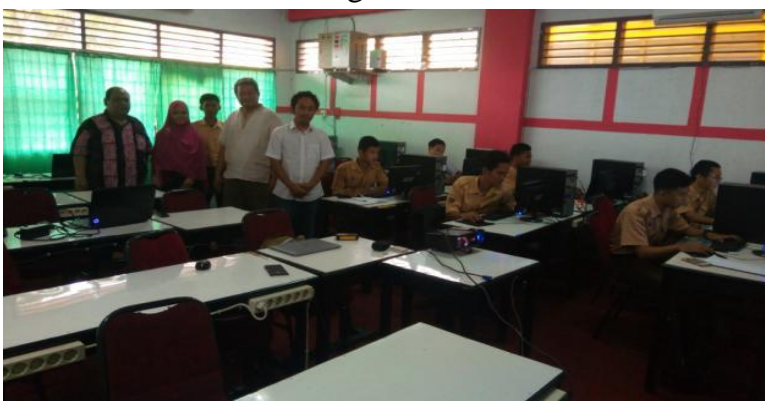

Gambar 4. Suasana Pelatihan di SMK Dwiwarna Medan

\section{KESIMPULAN DAN REKOMENDASI}

Kesimpulan yang dapat diambil dari kegiatan ini adalah diperlukan upaya menjembatani pengetahuan yang ada di kampus untuk disebarkan kepada masyarakat. Mitra didalam pengabdian ini menyambut baik karena transfer ilmu pengetahuan dan ketrampilan dapat membuat siswa memiliki skill yang dapat mereka manfaatkan dikemudian hari. Kegiatan dapat terlaksana dengan baik dan transfer ilmu kepada siswa diharapkan dapat menambah wawasan mereka kedepannya.

Sedangkan saran dari kegiatan ini adalah pelaksanaan kegiatan ini diharapkan terus berjalan dan menjangkau sekolah-sekolah yang membutuhkan informasi terbaru dari perguruan tinggi terutama untuk meningkatkan proses pembelajaran komputer di sekolah tersebut.

\section{UCAPAN TERIMA KASIH}

Penulis mengucapkan terima kasih kepada Universitas Sumatera Utara yang telah memberikan kesempatan untuk melaksanakan kegiatan ini melalui kontrak Nomor : 3224/UN5.2.3.2.1/PPM/2017, Tanggal 24 Juli 2017. Penulis juga mengucapkan terima kasih kepada mitra yaitu SMK Negeri 2 dan SMK 
Dwiwarna yang telah memberikan tempat untuk pelaksanaan kegiatan ini.

\section{DAFTAR PUSTAKA}

Manullang, Rio, 2015, Cara Mudah Mendisain Rumah Minimalis, PT. Elex Media Komputindo, Jakarta.

Wahana Komputer, 2014, Disain Interior dan Eksterior Rumah dengan Google Sketch Up, PT. Elex Media Komputindo, Jakarta. 